\title{
KEKUATAN PENGALAMAN KONSUMEN DAN KEPERCAYAAN TERHADAP MINAT BELI ULANG PADA TOKO HANDMADE ADDICTIVE
}

\author{
Lisa Pebrila', Asep M. Ramdan², Acep Samsudin ${ }^{3}$ \\ Mahasiswi Program Studi Administrasi Bisnis Universitas Muhammadiyah Sukabumi ${ }^{1}$ \\ Pengajar Program Studi Administrasi Bisnis Universitas Muhammadiyah Sukabumi ${ }^{2,3}$ \\ E-mail : lisapebrila123@gmail.com ${ }^{1}$,amr37.ramdan@gmail.com ${ }^{2}$,Chevysys_77@yahoo.com ${ }^{3}$
}

\begin{abstract}
The purpose of this study was to measure the interests of consumers and interest in the interest of repurchasing consumers of Handmade Addictive Cibatu Sukabumi Regency. The method used in this study uses a sampling method that is included in the method of random sampling by distributing 157 questionnaires consumers. The analysis technique used is multiple linear regression analysis techniques, including test coefficient of determination, multiple correlation coefficient, simultaneous test ( $F$ test), and partial test ( $t$ test). The results of the test coefficient of determination seen from the value (adjusted R2) of 0.980 can be interpreted as the experience of Consumer Experience and Trust in the interest of repurchase is $98.0 \%$. The remaining $0.02 \%$ was not approved by other studies. Based on multiple coefficient trials seen from the $\mathrm{R}$ value of 0.990 , shows a very strong real relationship between consumer experience and trust with repurchasing interest. Based on the $\mathrm{F}$ test the probability value sig. $0.00<0.05$ which means together Consumer Experience (X1) and Trust (X2) significant confidence in Repurchase Interests (Y). Based on the t test showing Consumer Experience (X1) has a significant effect on Repurchase Interest (Y), Trust (X2) has a significant effect on Repurchase Interest (Y).
\end{abstract}

Keywords: Consumer experience, trust, repurchase interest

\begin{abstract}
ABSTRAK
Tujuan penelitian ini adalah untuk mengukur pengaruh pengalaman konsumen dan kepercayaan terhadap minat beli ulang konsumen Handmade Addictive Cibatu Kabupaten Sukabumi. Metode yang digunakan dalam penelitian ini menggunakan metode sampling yang termasuk kedalam metode sampel random sampling dengan melakukan penyebaran kuesioner sebanyak 157 konsumen Handmade Addictive. Teknik analisis yang digunakan adalah teknik analisis regresi linear berganda, termasuk uji koefisien determinasi, koefisien kolerasi ganda, uji secara simultan (uji F), dan uji secara parsial (uji t).

Hasil dari uji penelitian ini adalah untuk mengukur pengaruh dari pengalaman konsumen dan kepercayaan terhadap minat beli ulang penelitian uji koefisien determinasi dilihat dari nilai (Adjusted $\mathrm{R}^{2}$ ) sebesar 0,980 hal ini diartikan bahwa pengaruh Pengalaman Konsumen dan Kepercayaan terhadap Minat beli ulang sebesar 98,0\%, Sisanya 0,02\% dipengaruhi oleh faktor lainnya yang tidak dijelaskan dalam penelitian ini. Dari hasil uji koefisien korelasi ganda dapat dilihat dari nilai $\mathrm{R}$ sebesar 0,990, menunjukan adanya hubungan yang sangat kuat antara pengalaman konsumen dan kepercayaan dengan minat beli ulang. Berdasarkan hasil uji $\mathrm{F}$ nilai probabilitas sig. $0,00<0,05$ yang berarti bahwa secara bersama-sama Pengalaman Konsumen $\left(\mathrm{X}_{1}\right)$ dan Kepercayaan $\left(\mathrm{X}_{2}\right)$ mempunyai pengaruh secara signifikan terhadap Minat Beli Ulang (Y). Sedangkan pada hasil uji t menunjukan bahwa Pengalaman Konsumen $\left(\mathrm{X}_{1}\right)$ mempunyai pengaruh signifikan terhadap Minat Beli Ulang $(\mathrm{Y})$, Kepercayaan $\left(\mathrm{X}_{2}\right)$ berpengaruh signifikan terhadap Minat Beli Ulang (Y).
\end{abstract}

Kata kunci : Pengalaman konsumen, kepercayaan, minat beli ulang 
Lisa Pebrila, Asep M. Ramdan, dan Acep Samsudin. Kekuatan Pengalaman...

\section{PENDAHULUAN}

Penelitian tentang minat beli ulang ini telah dikaji selama 20 tahun terakhir pada bidang indusri makanan dan minuman (Michael Setiomuliono et al., 2015), pada bidang Perdagangan (Athiyah Solihatun Nisa, 2018), pada bidang produksi (Nurhayati et al., 2012), pada bidang jasa (Wiliam Sutiono et al., 2015).

Industry pandai besi merupakan usaha pertukangan besi, dimana industri ini pada awalnya hanya membuat senjata tradisional saja. Seiiring dengan berjalannya waktu, perkembangan pembuatan pandai besi ini mulai merubah bentuk usahanya dengan mengembangkan pembuatan pandai besinya dengan berbagai jenis seperti, pisau sembelih, pisau dapur, tajak dan lain sebagainnya. Industri pada bidang pandai besi ini merupakan usaha yang dibangun oleh perorangan dan kelompok yang bergerak dibidang pertukangan besi. Yang dimana industri ini menunjukan peranan seseorang terhadap keahliannya yang di akui para pakar dibidang pandai besi. Keahlian pandai besi berawal pada pembuatan senjata tradisional misalnya: keris, parang, pedang yang dimana keahlian ini diturunkan secara turun temurun. Dengan perkembangan di jaman sekarang mulailah adanyanya peralihan yang awalnya hanya membuat senjata tradisional di tumbuh kembangkan dengan pembuatan alat-alat pertanian atau perkebunan.

Permasalahan yang sering muncul pada toko penjual perkakas ini salah satunya pada minat beli ulang konsumen. Permasalahan ini di duga disebabkan oleh pengalaman konsumen, dimana pada pengalaman tersebut bahwa belum sepenuhnya konsumen merasakan pengalaman yang positif saat sudah mengkonsumsi produk Handmade, yang mengatakan bahwa produk handmade ini yang menyebabkan konsumen merasa kecewa. baru saja digunakan beberapa kali ketajamannya cepat sekali berkurang, dan kualitas logam dari produk ini mudah sekali berkarat dan juga pengerjaan produknya kurang rapi yang dimana hal ini menyebabkan pengalaman awal konsumen dalam mengkonsumsi produk dari handmade ini kurang baik yang akan menurunkan tingkat kepercayaan dari konsumen terhadap produk itu sendiri karena 
E-Jurnal Ekonomi dan Bisnis Universitas Udayana 8.4 (2019): 341-354 pengalaman sebelumnya, yang dimana jika pengalaman yang diperoleh konsumen ini tidak baik dan menurunkan tingkat kepercayaan konsumen terhadap produk hal ini akan menyebabkan turunya minat beli ulang dari konsumen.

\section{Tinjauan Pustaka}

\section{Pengalaman Konsumen}

Pengalaman konsumen adalah suatu perasaan atau persepsi yang timbul dari seseorang setelah mereka menggunakan barang atau jasa yang mereka gunakan, (Yulita Leni, 2017), (Ika Pratama Kusumawati, 2013). Pengalaman Konsumen merupakan suatu interaksi yang terjadi antara konsumen dan produk, perusahaan atau bagian dari suatu organisasi yang menimbulkan reaksi. (Pramudita dan Japarianto, 2012).

Sementara itu, Pengalamn konsumen ialah suatu reaksi atau tanggapan dari para konsumen setelah mendapatkan reaksi mengenai apa yang sudah dirasakan baik secara langsung maupun tidak langsung (Meyer dan Schwager, 2012). Ika Pratama Kusumawati, 2013 menyatakan bahwa ada lima dimensi dari pengalaman konsumen yaitu, sebagai berikut:

1. Sense (panca indra), merupakan pengalaman yang dirasakan oleh konsumen mengenai tampilan fisik dari produk toko atau perusahaan tersebut (Rini, 2009), (Andreani, 2007)

2. Feel (perasaan), merupakan pengalaman yang dirasakan oleh konsumen melalui perasaan yang dirasakan langsung oleh konsumen setelah menggunakan produk atau jasa dari suatu toko atau perusaahaan tersebut (Alma, 2011), (Rini,2009)

3. Think (cara berpikir), merupakan pengalaman yang dirakan konsumen melalui cara berpikir konsumen dalam melakukan pembelian setelah mengkonsumsi produk atau jasa dari suatu toko atau perusahaan tersebut (Kenny Febrina Salim et al., 2014), (Ika Pramudita Kusumawati, 2013) 
Lisa Pebrila, Asep M. Ramdan, dan Acep Samsudin. Kekuatan Pengalaman...

4. Relate (pertalian), yaitu salah satu pengalaman yang dirasakan konsumen mengenai pendekatan secara individu dengan produk dan toko tersebut (Andreani. 2007), (Kenny Febrina Salim et al., 2014)

5. Act (tindakan), merupakan pengalaman konsumen yang terjadi setelah mendapatkan hasil dari interaksi yang terjadi dengan orang lain (Kustini, 2007), (Andreani, 2007)

Hubungan pengalaman konsumen terhadap Minat Beli Ulang menurut Elwin Novaris Adinata (2015), Yulita Leni (2017), Fredrick Alfian dan Peggy Hariawan (2016), Helena Hildaria (2017), Nurhayati \& Wahyu Wijaya Murti (2012), Muhammad Hafiz Sayuti \& Citra Kusuma Dewi (2015), Ika Pratama Kusumawati (2013), Fitria Handayani (2017), Agus Wahyono (2017), Malahayati \& Sorayanti Utami (2016), menyatakan bahwa, "pengalaman konsumen berpengaruh positif dan signifikan terhadap minat beli ulang”.

$\mathrm{H}_{1}$ : Pengalaman konsumen berpengaruh terhadap Minat beli ulang toko/perusahaan industri pandai besi (Handmade addictive).

\section{Kepercayaan}

Kepercayaan yang didefinisikan sebagai suatu keyakinan konsumen terhadap suatu produk barang maupun jasa. (Ramli Akbar Alamsyah, 2012). Selain itu kepercayaan dapat diartikan sebagai suatu kesediaan atau kesiapan dari suatu perusahaan untuk memenuhi kebutuhan konsumen yang sesuai dengan keinginan dari konsumen itu sendiri (Noorlaily Fitdiarini, 2015), Menurut Steven Darwin \& Yohanes Sondang Kunto (2014) menyatakan bahwa kepercayaan terdiri dari lima dimensi yaitu:

1. Benevolence, merupakan itikat baik dan keyakinan bahwa pada suatu pihak akan dilindungi serta tidak akan ada yang dirugikan oleh pihak yang dipercayai (Ramli Alamsyah, 2012), (Noorlaily Fitdiaini, 2015) 
E-Jurnal Ekonomi dan Bisnis Universitas Udayana 8.4 (2019): 341-354

2. Reliability, merupakan suatu kemampuan yang dapat diandalkan untuk memenuhi yang dibutuhkan oleh seseorang atau kelompok jika mereka membutuhkan (Ramli Alamsyah, 2012), (Noorlaily Fitdiaini, 2015)

3. Competence, yaitu kemampuan yang dimiliki oleh suatu pihak dari segi skill dan pengetahuan yang dimiliki untuk memenuhi kebutuhan pelanggan (Ramli Alamsyah, 2012), (Noorlaily Fitdiaini, 2015)

4. Honesty, yaitu sejauh mana pernyaataan atau ungkapan dapat ditepati (Ramli Alamsyah, 2012), (Noorlaily Fitdiaini, 2015)

5. Openness, merupakan suatu keterbukaan untuk memberitakan atau memberitahukan informasi yang dibutuhkan kepada konsumen (Ramli Alamsyah, 2012), (Noorlaily Fitdiaini, 2015)

Hubungan kepercayaan terhadap minat beli ulang Menurut Anindita Pramis Kurma (2012), Elwin Novaris Adinata (2015), Christoper Andretta Handono et al (2015), Norhermaya (2016), Ni Putu Widantari Suandana (2016), Ramli Akbar Alamsyah (2016), Moch Wildan Arifi (2016), Five Sulistiyani Rossanah (2014), Athiyah Sholihatun Nisa (2018), Riezal Aulia Hakim (2018), "bahwa kepercayaan berpengaruh positif signifikan terhadap minat beli ulang”.

$\mathrm{H}_{2}$ : Kepercayaan berpengaruh terhadap minat beli ulang pada toko/perusahaan industri pandai besi (toko Handmade Addictive).

\section{Minat Beli Ulang}

Minat beli ulang merupakan suatu persepsi konsumen dalam melakukan tindakan untuk konsumen melakukan pembelian ulang pada suatu produk/jasa. (Wahyu Wijaya Murti, 2012). Minat beli ulang merupakan suatu tidakan yang dilakukan oleh konsumen yang melakukan pembelian lebih dari satu kali. (Yulita Leni, 2017).

Nanda Mahardika, (2017) menyatakan bahwa minat beli ulang dapat diidentifikasi melalui indikator-indikator sebagi berikut: 
Lisa Pebrila, Asep M. Ramdan, dan Acep Samsudin. Kekuatan Pengalaman...

1. Minat transaksional, merupakan kecenderungan seseorang dalam melakukan pembelian produk/jasa (Nanda Mahardika, 2017), (Wahyu Wijaya Murti, 2012), (Yulita Leni, 2017)

2. Minat referensial, merupakan kecenderungan seseorang dalam merefensikan produk/jasa yang sudah dikonsumsinya kepada orang lain (Nanda Mahardika, 2017), (Wahyu Wijaya Murti, 2012), (Yulita Leni, 2017)

3. Minat preferensial, ialah minat yang menggambarkan prilaku seseorang yang memiliki preferensi untama pada produk tersebut. (Nanda Mahardika, 2017), (Wahyu Wijaya Murti, 2012), (Yulita Leni, 2017)

4. Minat eksploratif, pada minat ini menggambarkan prilaku seseorang yang selalu mencari informasi yang berhubungan dengan produk/jasa yang diminatinya yang mendukung hal positif mengenai produk/jasa tersebut (Nanda Mahardika, 2017), (Wahyu Wijaya Murti, 2012), (Yulita Leni, 2017)

Serta hubungan pengalaman pelanggan dan kepercayaan terhadap minat beli ulang Elwin novaris Adinata (2015), Menurut Ni Putu Widantari Suandana (2016), Helena Hildaria (2017), yang menyatakan "bahwa variabel pengalaman dan kepercayaan berpengaruh positif dan signifikan terhadap minat beli ulang”.

$\mathrm{H}_{3}$ : Pengalaman konsumen dan kepercayaan berpengaruh terhadap minat beli ulang pada toko/perusahaan industry pandai besi (toko Handmade Addictive).

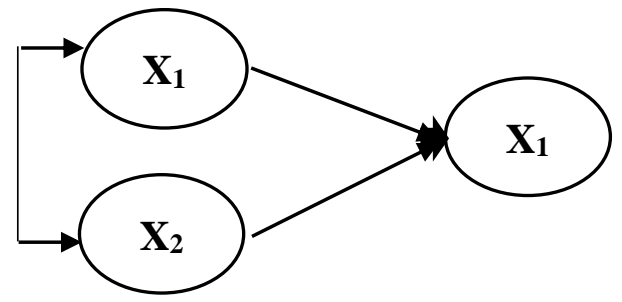

Gambar 1 Paradigma Penelitian 
Keterangan :

E-Jurnal Ekonomi dan Bisnis Universitas Udayana 8.4 (2019): 341-354

Variabel $\mathrm{X}_{1}=$ Pengalaman Konsumen

Variabel $\mathrm{X}_{2}=$ Kepercayaan

Variabel Y = Minat Beli Ulang

\section{METODE PENELITIAN}

Penelitian ini dilaksanakan pada Toko Handmade Addictive Cibatu Kabupaten Sukabumi. Metode yang digunakan pada penelitian ini yaitu dengan menggunakan jenis sampling yang termasuk kedalam sampel random sampling serta peneliti melakukan penyebaran kuesioner sebanyak 157 kepada konsumen. Teknik analisis yang digunakan adalah teknik analisis regresi linear berganda, dan untuk pengujian hipotesis adalah uji statistik secara parsial (uji t) dan uji secara simultan (uji F).

\section{Hasil Analisis Regresi Linear Berganda}

Regresi linear berganda ini mempunyai manfaat untuk meneliti suatu pengaruh dari beberapa variabel yang berkorelasi dengan variabel yang lain yang akan diuji. Dari hasil regresi linear berganda ini dapat dilihat pada tabel 1 sebagai berikut :

Tabel 1

Hasil Uji Regresi Linear Berganda

\begin{tabular}{|c|c|c|c|c|c|c|}
\hline \multicolumn{7}{|c|}{ Coefficients $^{\mathrm{a}}$} \\
\hline & & \multicolumn{2}{|c|}{$\begin{array}{c}\text { Unstandardized } \\
\text { Coefficients }\end{array}$} & \multirow{2}{*}{$\begin{array}{c}\begin{array}{c}\text { Standardize } \\
\mathrm{d}\end{array} \\
\text { Coefficients }\end{array}$} & \multirow[b]{2}{*}{$\mathrm{T}$} & \multirow[b]{2}{*}{ Sig. } \\
\hline \multicolumn{2}{|c|}{ Model } & $\mathrm{B}$ & Std. Error & & & \\
\hline \multirow[t]{3}{*}{1} & (Constant) & -.164 & .141 & & -1.167 & .245 \\
\hline & Pengalaman konsumen & .304 & .057 & .526 & 5.308 & .000 \\
\hline & Kepercayaan & .380 & .081 & .466 & 4.707 & .000 \\
\hline
\end{tabular}

Sumber : Data Primer (Kuesioner), 2019

Dari output uji regresi linear berganda diatas, maka dapat diperoleh persamaan sebagai berikut ini :

$$
Y=-0,164+0,304 X_{1}+0,380 X_{2}
$$


Lisa Pebrila, Asep M. Ramdan, dan Acep Samsudin. Kekuatan Pengalaman...

\section{Koefisien Determinasi $\left(\mathbf{R}^{2}\right)$}

Tabel 2

Hasil Koefisien Determinasi

Model Summary

\begin{tabular}{|l|r|r|r|r|}
\hline & & & & \multicolumn{2}{|c|}{$\begin{array}{c}\text { Std. Error of the } \\
\text { Estimate }\end{array}$} \\
\hline 1 & $\mathrm{R}$ & \multicolumn{1}{|c|}{ R Square } & \multicolumn{1}{c|}{ Adjusted R Square } & .568 \\
\hline
\end{tabular}

a. Predictors: (Constant), Kepercayaan, Pengalaman konsumen

Sumber : Data Primer (Kuesioner), 2019

Hasil tabel 2 diatas model summary besarnya adjusted $\mathrm{R}^{2}$ yaitu 0,980 ; maka hal ini berarti 98,0\% variasi minat beli ulang dapat dijelaskan oleh variasi dari dua variabel independen pengalaman konsumen dan kepercayaan serta sisanya $0.02 \%(100 \%-98,0 \%=0.02 \%)$ ini dari faktor yang tidak diteliti.

\section{Koefisien korelasi Ganda $(\mathbf{R})$}

Tabel 3

Hasil Koefisien Korelasi Ganda

Model Summary

\begin{tabular}{|l|r|r|r|r|}
\hline & & & & \multicolumn{2}{|c|}{$\begin{array}{c}\text { Std. Error of the } \\
\text { Estimate }\end{array}$} \\
\hline 1 & $\mathrm{R}$ & $\mathrm{R}$ Square & Adjusted R Square & .568 \\
\hline
\end{tabular}

Sumber : Data Primer (Kuesioner), 2019

Berdasarkan tabel 3 di atas bahwa hasil yang diperoleh angka $\mathrm{R}$ sebesar 0,990 hasil ini berada pada katagori 0,80-1,000. Hal ini menunjukan bahwa adanya hubungan yang sangat kuat antara pengalaman konsumen dan kepercayaan dengan minat beli ulang.

\section{Uji Signifikasi Secara Simultan (Uji F)}

Tabel 4

\section{Hasil Uji F}

$\mathrm{ANOVA}^{\mathrm{a}}$

\begin{tabular}{|l|l|r|r|r|r|r|}
\hline \multicolumn{2}{|l|}{ Model } & Sum of Squares & Df & Mean Square & \multicolumn{1}{c|}{ F } & Sig. \\
\hline \multirow{3}{*}{1} & Regression & 2438.344 & 2 & 1219.172 & 3774.285 & $.000^{\mathrm{b}}$ \\
\cline { 2 - 7 } & Residual & 49.745 & 154 & .323 & & \\
\cline { 2 - 7 } & Total & 2488.089 & 156 & & & \\
\hline
\end{tabular}

a. Dependent Variable: Minat Beli Ulang

b. Predictors: (Constant), Kepercayaan, Pengalaman konsumen

Sumber : Data Primer (Kuesioner), 2019 
E-Jurnal Ekonomi dan Bisnis Universitas Udayana 8.4 (2019): 341-354 Berdasarkan tabel 4 di atas, hasil uji F yang telah dilakukan diperoleh nilai sig. 0,000 < 0,05; nilai $F_{\text {hitung }} 3774,285>F_{\text {tabel }}$ 3,05. Artinya bahwa pengalaman konsumen dan kepercayaan secara bersama-sama (simultan) berpengaruh terhadap minat beli ulang.

\section{Uji Signifikasi Secara Parsial (Uji t)}

Tabel 5

\section{Hasil Uji t}

\section{Coefficients $^{\mathrm{a}}$}

\begin{tabular}{|c|c|c|c|c|c|c|}
\hline & & \multicolumn{2}{|c|}{$\begin{array}{c}\text { Unstandardized } \\
\text { Coefficients }\end{array}$} & \multirow{2}{*}{$\begin{array}{c}\begin{array}{c}\text { Standardized } \\
\text { Coefficients }\end{array} \\
\text { Beta }\end{array}$} & \multirow[b]{2}{*}{$\mathrm{T}$} & \multirow[b]{2}{*}{ Sig. } \\
\hline \multicolumn{2}{|c|}{ Model } & $\mathrm{B}$ & Std. Error & & & \\
\hline \multirow[t]{3}{*}{1} & (Constant) & -.164 & .141 & & -1.167 & .245 \\
\hline & Pengalaman konsumen & .304 & .057 & .526 & 5.308 & .000 \\
\hline & Kepercayaan & .380 & .081 & .466 & 4.707 & .000 \\
\hline
\end{tabular}

a. Dependent Variable: Minat Beli Ulang

Sumber : Data Primer (Kuesioner), 2019

hipotesis uji t yang telah diperoleh dapat dilihat bahwa pada variabel pengalaman konsumen nilai sig. $0,000>0,05$; nilai $\mathrm{t}_{\text {hitung }} 5.308>\mathrm{t}_{\text {tabel }} 1.97549$, hal ini dapat diartikan bahwa pengalaman konsumen mempunyai pengaruh signifikan secara parsial, dan variabel kepercayaan nilai sig $0,000<0,05$; nilai $\mathrm{T}_{\text {hitung }} 4.707>\mathrm{t}_{\text {tabel }} 1.97549$, hal ini dapat diartikan bahwa kepercayaan berpengaruh positif dan signifikan secara parsial terhadap minat beli ulang.

\section{PEMBAHASAN}

\section{Hasil Uji Hipotesis}

$\mathrm{H}_{1}$ :Pengalaman konsumen berpengaruh terhadap minat beli ulang pada perusahaan industri dagang pandai besi (toko Handmade Addictive).

$\mathrm{H}_{0}$ :Tidak adanya pengaruh signifikan antara pengalaman konsumen terhadap minat beli ulang pada perusahaan industry dagang pandai besi (toko Handmade Addictive). 
Lisa Pebrila, Asep M. Ramdan, dan Acep Samsudin. Kekuatan Pengalaman...

Ha :Adanya pengaruh positif dan signifikan antara pengalaman konsumen terhadap minat beli ulang pada perusahaan dagang industri pandai besi (toko Handmade Addictive).

Pengalaman konsumen memiliki pengaruh yang positif dan signifikan terhadap minat beli ulang (Y) secara parsial. Hasil tersebut dapat dibuktikan dari hasil pengujian uji t yang menunjukan nilai sig. $0,000>0,05$; nilai thitung $5.308>\mathrm{t}_{\text {tabel }} 1.97519$, maka dari itu dapat disimpulkan bahwa $\mathrm{H}_{0}$ ditolak dan $\mathrm{H}_{\mathrm{a}}$ diterima. Hal ini menunjukan bahwa pengalaman konsumen pada perusahaan dagang industry pandai besi memberikan nilai positif dalam mempengaruhi minat beli ulang pada konsumen.

$\mathrm{H}_{2}$ : Kepercayaan berpengaruh terhadap minat beli ulang pada perusahaan industri dagang pandai besi (toko Handmade Addictive).

$\mathrm{H}_{0}$ : Tidak adanya pengaruh signifikan antara kepercayaan terhadap minat beli ulang pada perusahaan jasa industri dagang pandai besi (toko Handmade Addictive).

Ha : Adanya pengaruh positif dan signifikan antara kepercayaan terhadap minat beli ulang pada perusahaan dagang industri pandai besi (toko Handmade Addictive).

Kepercayaan memiliki pengaruh yang positif dan signifikan terhadap minat beli ulang (Y) secara parsial. Dimana hal ini dibuktikan dari hasil pengujian uji t yang menunjukan nilai sig. $0,000<0,05$; nilai $\mathrm{T}_{\text {hitung }} 4.707>\mathrm{t}_{\text {tabel }} 1.97519$, hal ini dapat disimpulkan bahwa $\mathrm{H}_{0}$ ditolak dan $\mathrm{H}_{\mathrm{a}}$ diterima. Maka hal ini menunjukan bahwa kepercayaan pada perusahaan dagang industry pandai besi memberikan nilai positif dalam mempengaruhi minat beli ulang.

$\mathrm{H}_{3}$ : Pengalaman konsumen dan kepercayaan berpengaruh terhadap minat beli ulang pada perusahaan dagang industri pandai besi (toko handmade addictive).

$\mathrm{H}_{0}$ : Tidak adanya pengaruh signifikan antara pengalaman konsumen dan kepercayaan terhadap minat beli ulang pada perusahaan dagang industri pandai besi (toko handmade addictive). 
Ha : Adanya pengaruh positif dan signifikan antara pengalaman konsumen dan kepercayaan terhadap minat beli ulang pada perusahaan dagang industri pandai besi (toko handmade addictive).

Pengalaman konsumen dan kepercyaan mempunyai pengaruh yang positif dan signifikan terhadap minat beli ulang (Y) secara simultan. Hal ini dapat dibuktikan dari hasil pengujian uji F yang menunjukan nilai sig $0,000<0,05$; nilai $F_{\text {hitung }} 3774,285>F_{\text {tabel }} 3,05$, hal ini dapat disimpulkan bahwa $\mathrm{H}_{0}$ ditolak dan $\mathrm{H}_{\mathrm{a}}$ diterima. Pada hasil ini dapat disimpulkan bahwa pengalaman konsumen dan kepercayaan berpengaruh signifikan secara bersama-sama (simultan) terhadap minat beli ulang.

\section{Hasil Analisis Regresi Bersama-sama}

Berdasarkan pada hasil analisis regresi berganda uji F dengan tingkat signifikan sebesar 0,05 (5\%) menunjukan bahwa variabel Pengalaman Konsumen $\left(\mathrm{X}_{1}\right)$ dan Kepercayaan $\left(\mathrm{X}_{2}\right)$ berpengaruh secara bersama-sama terhadap Minat Beli Ulang (Y). Hal ini ditunjukan dengan hasil nilai sig $0,000<0,05$; nilai $F_{\text {hitung }} 3774,285>F_{\text {tabel }} 3,05$. Nilai Koefisien determinasi $\left(R^{2}\right)$ diperoleh hasil dari variabel Pengalaman Konsumen $\left(\mathrm{X}_{1}\right)$ dan Kepercayaan $\left(\mathrm{X}_{2}\right)$ mempengaruhi sebesar 0,980 (98,0\%) terhadap Minat Beli Ulang (Y), sisanya $0.02 \%$ dari faktor yang tidak bahas dan diteliti. Hal ini dapat disimpulkan bahwa konsumen akan melakukan pembelian ulang pada toko tersebut atas segala pengalaman yang dirasakaan konsumen pada saat melakukan pembelian ulang dimana perusahaan harus memberikan kesan terbaik untuk konsumen seperti memberikan produk yang sesuai dengan harapan konsumen, membuat produk dengan kualiats yang terbaik yang tidak mudah rusak, dan bisa membuat konsumen untuk percaya terhadap produk nya tersebut seperti dalam hal menjaga hubungan baik dan memberikan pelayanan yang baik kepada konsumen dalam hal beritikat baik, integritas, dan kompetensi yang di berikan oleh Toko HANDMADE ADDICTIVE Cibatu Kabupate Sukabumi. 
Lisa Pebrila, Asep M. Ramdan, dan Acep Samsudin. Kekuatan Pengalaman...

\section{Pengaruh Pengalaman Konsumen $\left(\mathrm{X}_{1}\right)$ terhadap Minat Beli Ulang (Y)}

Berdasarkan hasil analisis data yang didapat pada uji t Pengalaman konsumen $\left(\mathrm{X}_{1}\right)$ dengan Minat beli ulang (Y) menunjukan bahwa nilai thitung sebesar 81.380 dan $\mathrm{t}$ tabel $(\alpha=0,05)$ diperoleh hasil $t_{\text {tabel }}$ 1.97549. Hasil signifikasi yang diperoleh $0,000>0,05$; nilai thitung $5.308>$ $\mathrm{t}_{\text {tabel }} 1.97549$ maka pengaruh dari $\left(\mathrm{X}_{1}\right)$ terhadap $(\mathrm{Y})$ signifikan. Dari hasil yang diperoleh dapat disimpulkan bahwa Pengalaman Konsumen berpengaruh signifikan terhadap Minat Beli Ulang. Hal ini menunjukan bahwa konsumen yang memberikan tanggapan yang baik pada pengalaman konsumen dalam hal penglihatan (panca indra), perasaan (feel), think (cara berpikir), relate (, (act (tindakan) hal ini sudah mampu menjadi membentuk konsumen untuk melakukan pembelian ulang pada Toko HANDMADE ADDICTIVE Cibatu Kabupaten Sukabumi.

\section{Pengaruh Kepercayaan $\left(\mathrm{X}_{2}\right)$ terhadap Minat Beli Ulang ( $\left.Y\right)$}

Berdasarkan hasil analisis data yang diperoleh dari uji t Kepercayaan $\left(\mathrm{X}_{2}\right)$ dengan Minat beli ulang (Y) menunjukan bahwa nilai thitung sebesar 79.990 dan t tabel $(\alpha=0,05)$ diperoleh hasil $t_{\text {tabel }}$ 1.97549. Nilai signifikasi yang didapat $0,000<0,05$; nilai $\mathrm{T}_{\text {hitung }} 4.707>\mathrm{t}_{\text {tabel }} 1.97549$ maka pengaruh $\left(\mathrm{X}_{2}\right)$ terhadap $(\mathrm{Y})$ signifikan. Dari hasil yang diperoleh dapat disimpulkan bahwa Kepercayaan berpengaruh signifikan terhadap Minat Beli Ulang. Hal ini menunjukan bahwa konsumen yang memberikan tanggapan baik terhadap kepercayaan yang baik dalam hal beritikat baik untuk melayani dan memenuhi kebutuhan konsumen dengan baik, integritas kejujuran penjual untuk mempertahankan konsumennya serta kompetensi untuk membantu konsumen dalam melakukan sesuatu yang sesuai kebutuhannya hal ini dapat mendorong dan membuat konsumen tetap memiliki kepercayaan dalam benaknya terhadap perusahaan serta produk yang dikeluarkan untuk melakukan pembelian ulang pada Toko HANDMADE ADDICTIVE Cibatu Kabupaten Sukabumi. 


\section{KESIMPULAN}

Secara parsial, bahwa semua Variabel pengalaman konsumen dan variabel kepercayaan berpengaruh positif dan signifikan terhadap Minat Beli Ulang pada toko HANDMADE ADDICTIVE Cibatu Kabupaten Sukabumi.

Berdasarkan dari hasi peungujian uji $\mathrm{F}$, pada variabel pengalaman konsumen dan kepercayaan mempunyai pengaruh yang signifikan secara bersama-sama (simultan) terhadap minat beli ulang pada toko HANDMADE ADDICTIVE Cibatu Kabupaten Sukabumi.

\section{REFERENSI}

Adinata, Novaris, E, 2010, "Pengaruh Pengalaman, Kualitas Website, dan Kepercayaan terhadap Niat pembelian Ulang", Artikel Ilmiah.

Adrian, Palmer., et al, (2000) "Equity and Repurchase Intention Following Service Failure", Journal Of Service Marketing, Vol. 14 Issue :6, pp.513528, http://doiorg/10.1108/0887640010347624.

Alamsyah, AA, 2016, "Pengaruh Kepuasan dan Kepercayaan Pelanggan terhadap Niat Pembelian Ulang di Toko Online", Jurnal.

Alfian, Fredick, et al, 2016, “Analisis Pengaruh Customer Experience terhadap Minat Beli Ulang pada Wiki Koffie Bandung”, e-Procceding of Management, Vol.3, No.1 April 2016.

Arifi, Wildan, M, 2016, "Pengaruh Citra Merek, Kepercayaan Merek dan Kepuasa Pelanggan terhadap Minat Beli Ulang Pakaian Wanita The Executive di Surabaya", Artikel Ilmiah.

Chao-Min Chiu, et al., (2009), "Determinants Of Custmer Repurchase Intention In Online Shoping”, Online Information Review, Vot 33 Issue: 4, pp.761-84, http://doi-org/10.1108/14684520910985710.

Darwin, Steven, et al, 2014, “Analisis Pengaruh Kualitas Pelayanan terhadap Loyalitas Pelanggan dengan Kepuasan Pelanggan dan Kepercayaan Pelanggan sebagai Variabel Intervening", Jurnal Manajemen Pemasaran Petra, Vol.2, No. 1, 2014.

Febrina, Kenny S. et al., 2014. "Pengaruh customer experience dan kepercayaan terhadap kepuasan konsumen di TX Travel Klampis. Jurnal.

Hafiz, MS, \& Kusuma, CD, (2015), "Analisis Pengaruh Customer Experience terhadap Minat Beli Ulang Konsumen pada Kafe Nom Nom Eatery Bandung”, ISSN : 2355-9357, eProcceding of Management : Vol.2, No.2 Agustus 2015 | page 1932.

Hakim, AR, (2018), "Analisis Pengaruh Desain Produk dan Kepercayaan terhadap Minat Beli Ulang Tas Consina Melalui Kepuasan Sebagai Variabel Intervening”, Jurnal.

Handono, CA, et al., Analisis Faktor-Faktor yang Mempengaruhi Minat Beli Ulang pada Produk McDonald di Surabaya, Jurnal GEMA AKTUALITA, Vol. 4, No. 1, Juni 2015.

Handayani, Fitria, (2017) "Pengaruh Dimensi Experiental Marketing terhadap Minat Beli Ulang Konsumen pada Owl Café di Bandar Lampung", Skripsi. 
Lisa Pebrila, Asep M. Ramdan, dan Acep Samsudin. Kekuatan Pengalaman...

Hildaria, Helena, "Pengaruh Kepercayaan, pengalaman Berbelanja, Dan Kemudahan Transaksi Terhadap Minta Belanja Online, Jurnal, 2017, Hal. 22.

Iqbal, M, Azhari., Dhlan, Fanami., \& M. Kholik Mawardi. 2015. Pengaruh Customer Experience terhadap Kepuasan Pelanggan dan Loyalitas Pelanggan, Jurnal Administrasi Bisnis, Vol.28, No.1

Kumara, AP, 2012, "Analisis Pengaruh Kepercayaan dan Kepuasan Merek pada Niat Pembelian Ulang terhadap Pengecer”, Skripsi.

Kusumawati, Pratama, L, 2013, "Analisis Pengaruh Customer Experience terhadap Minat Beli Ulang”, Skripsi.

Kotler, dan Keller, (2012), Manajemen Pemasaran, Edisi 12. Jakarta : Penerbit Erlanggan.

Leni, Yulita, 2017, "Pengaruh Customer Experience terhadap Minat Beli Ulang”, Skripsi.

Malahayati, \& Utami, S, "Pengaruh Experiental Marketing terhadap Minat Beli Ulang yang Dimediasi oleh Kepuasan Pelanggan pada Konsumen Café Socolate di Kabupaten Pidie Jaya Aceh", Jurnal Ilmiah Mahasiswa Ekonomi Manajemen, Vol. 1, No.1, November 2016: 183-201.

McKnight, D.H., Choudury, V., \& Kalmar, C.J. (2002)a. "Developing and Validating Trust Measure For e-Commerce : an Integrative Typology", Information System Research, 13 (3), 334-59 =. (2002)b. "The Impact Of Initial Trust Customer On Intention to Transact With a web site. A Trust Building Model", Journal Of Strategic Information System. 1193-4), 297-323.

Naswemoadeli, Ling. \& Magnati. 2013. Evaluating The Impact on Purchase Intention, International Journal of Business and Managemen, Vol. 8, N0.6.

Nisa, AS, (2018), "Pengaruh Harga, Kepercayaan dan Kualitas Pelayanan terhadap Minat Beli Ulang dalam Berbelanja Online di Instagram", Skripsi.

Nurhayati, "Analisis Faktor-Faktor yang Mempengaruhi Minat Beli Ulang Masyarakat terhadap Produk Handphone”, Value Added, Vol.8, No.2, Maret 2012-Agustus 2012.

Philip K.Heller, et al (2003) "Customer Repurchase Intention = A general structural equation model”, European Journal Of Marketing, Vol.37 Issue: 11/12, pp. 1762-1800, http://doi.Org/10.1108/03090560310495456.

Pramudita dan Japarianto, 2012, "Analisa Pengarh Customer Value dan Customer Experience terhadap Customer Satisfaction di de Kasteel Rerto Surabaya”, Volume 1, No. 1.10 July 2012.

Riduwan, (2014). Dasar-Dasar Statistika, Bandung: Alfabeta

Rini, E.S. (2009). "Menciptakan pengalaman konsumen dengan experiental marketing”, Jurnal Manajemen Bisnis, Vol. 2, No. 1, pp. 15 - 20, Januari 2009.

Rosannah, FS, "Pengaruh Kepercayaan dan Kepuasan terhadap Merek pada Niat Membeli Ulang”, Jurnal Siasat Bisnis, Issn: 0853-7665, Vol. 18, No.1, Januari 2014, Hal: 6380.

Setiomuliono, Michael, et al., "Analisis Pengaruh Promosi Harga terhadap Minat Beli Ulang dengan Kepuasan sebagai variabel perantara Di De Boliva Surabaya Town Square”, Jurnal, 2015.

Sugiyono, (2011). "Metode Penelitian Kuantitatif Kualitatif Dan R\&D”, Cetakan Ke 13, Alfabeta, Bandung.

Sugiyono, 2013, Metode Penelitian Kuantitatif, Kualitatif dan R\&D, Bandung: Alfabeta.

Sugiyono, (2014). Metode Penelitian Bisnis, Bandung: Alfabeta.

Wahyono, Agus, 2017, “Analisis Pengaruh Customer Experience terhadap Minat Beli Ulang Konsumen pada Dress Up Laundry \& Dry Cleaning Service Cabang Benhil Jakarta Pusat", Jurnal Manajemen. 